Historic, Archive Document

Do not assume content reflects current scientific knowledge, policies, or practices. 



\section{Long Island}

Lawn Grass Seed

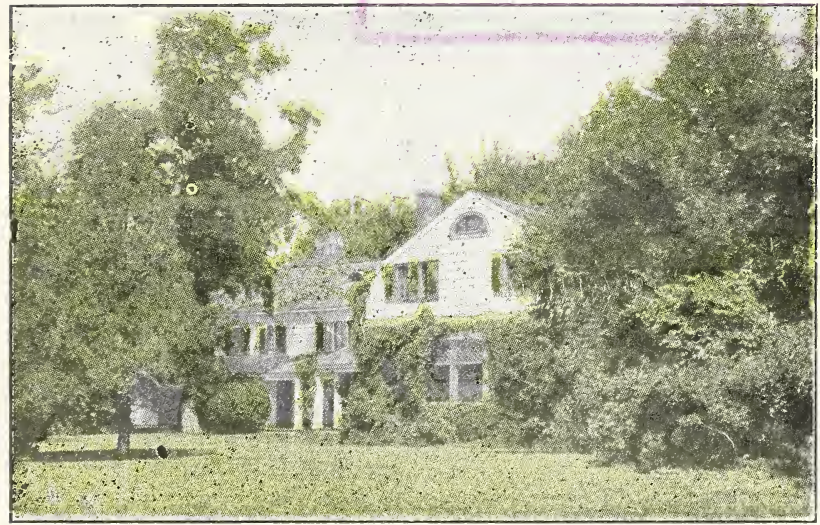

FLUSHING NURSERIES, Inc. FLUSHING, NEW YORK 


\section{Long Island Lawn Grass Seed}

$\mathrm{H}^{\mathrm{OW}}$ often do we stop to admire a well designed house surrounded by artistically treated grounds, the most essential feature of which is the luxuriant lawn? This is the canvass upon which the landscape picture is painted. Without a good lawn the home grounds, no matter how well designed, are lacking in their main feature.

\section{The Long Island Lawn Grass} Seed produces a perfect, enduring lawn that is often ready for cutting in from three to four weeks from the time of sowing. This mixture 
is a compound of various $\mathrm{f}$ in e leaved varieties that flourish under adverse conditions. It has been used by us with great success, for, being composed of hardy grasses only, it makes a thicker and more permanent turf each year. Law n s produced by this brand rival the famous lawns of Europe.

Long Island Lawn Grass Seed is, comparatively speaking, cheaper than other lawn seeds sold under fancy names, because it gives immediate and lasting results.

Price for Long Island Lawn Seed per bushel, $\$ 5.00$
$\$ \% 7.50$

SOLD EXCLUSIVELY BY THE

FLUSHING NURSERIES, INC. FLUSHING, NEW YORK 


\section{Our Landscape De-}

partment is prepared to furnish estimates for making new and removating old lawns. 